\title{
Research on the Development Model of Horse Racing Industry in Wuhan From the Perspective of Value Chain
}

\author{
Zhichao Ma, Yingyue Hu \\ The School of Physical Education, Wuhan Business University, Wuhan, China \\ 133383926@qq.com \\ 337584093@qq.com
}

\begin{abstract}
With the continuous development of horse racing and the expansion of event scale, the number of people participating in Chinese horse racing has witnessed an exponential increase. In this context, the industries derived from horse racing enjoy a growing development potential. For instance, Wuhan Speed Horse Racing Competition has been held for sixteen times since 2002 and has become one of the brand sports events of Wuhan. Compared with foreign countries, however, the development of Wuhan's horse racing industry is still at the initial phase. Thus it is necessary for Wuhan to learn mature development experience from foreign industries and set up a horse racing development model that is suitable for Chinese national conditions. Based on value-chain theory, this thesis analyzes the status of Wuhan's horse racing industry and future development direction, and then it explores the competitive advantages of Chinese horse racing enterprises in the industry to provide a referential basis for improving the operation, management and profiting capacity of Wuhan's horse racing industry.
\end{abstract}

Keywords-Wuhan's horse racing industry; Value chain; Development model

\section{INTRODUCTION}

Horse racing is a traditional sports event of China and has a long history of development. A large number of horse-racing events have been held since the reform and opening up. In particular, China (Wuhan) International Horse Racing Festival and National Horse Racing Championship have been held since 2002, which facilitates the rapid development of Wuhan's horse racing industry. Through years' development, Wuhan's horse racing industry has reached a large scale and enjoyed much improvement in infrastructure, horse racing platform, event system and event operation. Restricted by macroscopic policies, management systems, national conditions, cultural traditions and consumption habits, Wuhan fails to form a mature horse racing industry and faces increasingly prominent problems, including inadequate development of horse race consumption market. [1] This thesis analyzes the status quo and future development of Wuhan's horse race industry from the perspective of value chain theory. Based on exploring the competitive advantages of Chinese horse racing enterprises in the industry, the thesis aims to provide reference for improving the operation, management and profiting capacity of Wuhan's horse racing industry.

\section{STRUCTURAL ANALYSIS OF WUHAN's HORSE RACING INDUSTRY}

The horse racing industry consists of the horse-racing ontology industry and derived industries. It is subdivided into mutually connected branch industries. The development of horse racing industry is driven by the ontology industry (including horse riding fitness industry and horse-racing performance \& competition industry) [2]. The horse riding fitness industry aims to meet residents' growing demands for fitness and cultural entertainment, while the horse-racing performance \& competition industry mainly provides visual enjoyment to residents. With the increase of disposable incomes and free time, residents' consumption enjoys a blowout increase in demands for fitness and entertainment. Correspondingly, the horse racing ontology industry ushers in an important opportunity for development. In addition, the industries which are derived from the ontology industry, including the horse supply industry, horse advertisement industry, horse media industry, horse financial industry (including sponsorship, lottery and insurance) and horse tourism industry, also have a huge space for development. The popularization and promotion of horse racing will keep fostering residents' enthusiasm for participating in horse racing and attract more people to participate in horse racing, which drives the development of horse-racing ontology industry. Currently speaking, the horse racing industry has a wide market prospect and strong industrial linkage effect. Hence there is much space for the horse-racing ontology industry and derived industries to enjoy rapid growth. In conclusion, Wuhan's horse racing industry will inevitably serve as a new engine for driving the development of the third industry. 


\section{DEVELOPMENT MODEL ANALYSIS OF WUHAN'S HORSE RACING INDUSTRY}

\section{A. Value Chain Positioning Model}

Analyzed from the perspective of value chain theory, Wuhan's horse racing enterprises can only make correct market positioning for current market situation and form unique competitive advantages based on finding the most valuable key link of value chains. Hence Wuhan's horse racing enterprises should focus on developing core competiveness in subsequent development [3].

\section{1) Developing Wuhan's Horse Racing Brand Event}

World-known horse racing events, including American Kentucky Derby Festival, Australian Melbourne Cup and UAE Dubai Cup, are held in countries where the horse racing industry is highly developed. If Wuhan energetically develops its horse racing brand events, it will create good social effect, promote the point to the surface, facilitate the sustainable development of Chinese horse racing industry and expand the international communications of Chinese horse racing industry. To create Wuhan's horse racing into a brand and improve its influences, the promotions of horse culture is indispensable. Local government should promote Wuhan's horse racing events based on Chu culture and combine the competition culture with local culture through multiple channels, thereby creating a horse racing brand event with $\mathrm{Chu}$ cultural characteristics.

\section{2) Energetically Developing Horse-racing Lottery} Industry

Chinese tend to have misunderstandings of horse-racing lottery. In fact, the horse-racing lottery industry is an integral component of the horse-racing industry structure. Hence China should energetically support and develop horse-racing lottery industry to optimize the structure of Chinese horseracing industry. Compared with other horse-racing cities in China, Wuhan enjoys obvious policy advantages in developing horse-racing industry. It is thus necessary for Wuhan's horse racing industry to seize the opportunity of trial city for horse-racing industry and make preparation for technological system, talent allocation, relevant legislation and industrial organization. In addition, the Chinese government should promote the important roles of horse-racing lottery to correct residents' wrong opinion that horse-racing lottery is gambling. More importantly, the government should provide more support to horse racing lottery industry regarding capital, policy and cultural promotion, perfect the regulation and laws on selling horse racing lotteries and set up a sound supervision mechanism for selling horse racing lotteries [4].

\section{B. Value Chain Extension Model}

The value chain extension model refers to an enterprise develops business towards front-end and rear-end industrial chains to save operational costs and find new points of profit growth. As modern people's consumption concepts keep changing, consumers pay an increasing emphasis over the satisfaction towards services, such as the spiritual pleasure and inner satisfaction of watching a horse-racing event. Similarly, a satisfactory riding experience brings both physical health and spiritual happiness to members. To attract more attention and stimulate more people's consumption, Wuhan's horse racing industry should be devoted to holding horse-racing events of a higher level and improving the audience's consumption satisfaction. To attract more consumers, the horse racing and riding industry should improve service quality and consumers' satisfaction towards riding [5].

1) Energetically developing horse-racing service industry and actively guiding horse-racing consumption

With the constant upgrade of consumption structure, Wuhan's service industry enjoys rapid development. In the horse-racing industrial chain, horse-racing service industry, including horse-riding fitness industry and horse-racing performance \& competition industry, is closest to consumers. As an important component of horse racing industry, it serves as a powerful engine for developing horse racing industry. Wuhan's modern horse-racing industry enjoys a late start, which results in an incomplete and non-standard horse-racing market and undeveloped horse racing service industry. With rapid economic development, Wuhan's horse racing service industry meets huge development opportunities and space, and people have growing demands for horse racing service industry. In addition, the priorities of optimizing horse-racing industrial structure lie in developing the horse-racing service industry. Developing the horse-racing service industry not only meets the demands for upgrading Wuhan's horse-racing industry, but also the real demands for developing Wuhan's horse-racing industry in the current phase. The development of horse racing service industry not only drives the talent cultivation of riders, horse trainers and horse doctors, but also facilitates the prosperity of horse breeding and horse-racing supplies industry. The horse-racing service industry may be taken as the leader of Wuhan's horse racing industry to create a horse-culture that meets the public's demands, foster the public's enthusiasm for horse-racing and create an active and healthy life style. This will eventually facilitate the reasonable flows of production elements in Wuhan's horse-racing industry chains.

\section{2) Promoting and Popularizing Horse Racing Culture}

Currently, Chinese pay inadequate attention to horseracing activities. On the contrary, the horse racing industry makes huge contribution to the economic development of many developed countries. For example, the economic output of American horse racing industry exceeds that of Hollywood entertainment industry. For another example, the Japanese horse racing industry generates the annual revenues of 30 40 billion yuan, $17 \%$ of which is used to support Japanese agricultural development. However, many Chinese hold wrong opinions of horse-racing lottery, mistakenly believing that horse-racing lottery is gambling. It is thus necessary to attract residents' attention to the horse racing industry, correct the public's misunderstanding of the horse-racing industry and teach residents the distinctive differences between horseracing lottery and gambling. The precondition of achieving these objectives lies in energetic cultural promotion. It requires the common efforts of the government, horse-racing association and horse-racing enterprises to achieve good communication effect through traditional media and new media. 


\section{Value Chain Integration Model}

The value of Wuhan's horse-racing industry is still at the initial phase and the value chain has many weak links. To seize the initiative in the future and create healthy industrial chains, Wuhan's horse racing industry should actively make up for weak links, integrate diverse resources and make joint efforts with government, corporate, organization and universities.

1) Improving the legal system, improving the supervision mechanism and creating a favorable environment for development

The credibility of Chinese sports industry has decreased in recent years, which is resulted from a series of soccer frauds and black whistles scandals. Conversely, Japan and America, where the horse-racing industry is highly developed, have complete regulations and laws on the horse-racing industry. Wuhan's governmental management departments and horseracing associations should actively promote the institutional construction of horse-racing industry, such as perfecting the regulations and laws on horse-racing athletic performance and horse-racing entertainment riding, to normalize market behaviors. It is necessary to eliminate frauds in horse-racing events with scientific and reasonable supervision mechanism and perfect legal regulations. Only a fair and just environment for horse racing can facilitate the healthy and orderly development of Wuhan's horse-racing industry and attract more resources to invest in horse-racing industry.

2) Accelerating the development of horse-racing supply market

China is a powerful manufacturing country and the products made in China are sold throughout the world. Located in central China, Wuhan enjoys an advantaged geographical position in developing horse-racing supply industry and currently manufactures a rich variety of horseracing supplies. According to the analysis of China International Professional Horse Sports \& Leisure Industries Exhibition held in recent years, global reputed horse product suppliers are optimistic about the Chinese market and ready to sell in China. Moreover, many horse-product manufacturers plan to relocate or set up their industries to China for manufacturing and sales. It is necessary for Wuhan's horse racing supply manufacturers to take advantage of this opportunity, promote brand strategies and support the construction Wuhan's horse-racing supply brands. In addition, these companies should enhance their R\&D efforts and keep improving the scientific and technological elements of Wuhan's horse-racing suppliers. Moreover, these companies should meet the demands in horse-racing supplier market and manufacture best-selling products needed by the market to improve the international reputation and competiveness of Wuhan's horse-racing supplier industry. talents

3) Optimizing the structure of professional horse-racing

The structural optimization of Wuhan's horse-racing industry requires accumulating a large amount of human capital. It is because talent is a crucial factor in all phases of industrial development. The talent structure includes the number and quality of talents. However, Wuhan's horse- racing industry only has less than 10,000 professional talents and lacks a batch of high-level professional horse-racing talents. The fundamental reason is that Chinese education on horse-racing and training time are inadequate. As a result, the deficiency of talents has been a bottleneck that restricts the rapid development of Wuhan's horse-racing industry. As of the present, only Wuhan Business University has provided majors related to horse racing. Wuhan should combine the efforts of governments, universities and enterprises to cultivate more talents that meet the prosperous development of horse-racing industry. For instance, universities should cooperate with enterprises to cultivate horse-racing talents and enhance the connections between more powerful horse-racing enterprises and institutes of physical education. In addition, Wuhan should cultivate a batch of high-quality skilled talents who grasp theories on horse-racing industry and the practice of horse-racing sports through other channels, including professional training, positional training, on-the-job training and recruitment introduction. Secondly, Wuhan should adopt effective policies and measures to introduce high-quality horse-racing talents from America, Japan and other countries with a developed horse-racing industry. For one thing, advanced foreign concepts and management methods may serve as valuable reference. For another, it facilitates the growth of management talents of horse-racing industry in Wuhan.

\section{ADVICE ON DEVELOPING WUHAN'S HORSE-RACING INDUSTRY}

Wuhan's horse-racing industry has enjoyed rapid development in recent years. Thanks to the valuable experience of holding large-scale horse-racing events, the horse-racing industry has made rapid progress in event infrastructure environment and event organization level. Nowadays, the cultivation of horse-racing market has made an active effect, which means horse racing is developing towards increasingly brand-based and industrialized [6]. Currently speaking, the structure of Wuhan's horse-racing industry needs further perfection and the industrial development remains at a low level. It is necessary to adopt the following advice to facilitate the linkage development of Wuhan's horseracing and relevant industries.

\section{A. Enhance International Communications and Make an Institutional Reform}

Although Wuhan's horse racing activities enjoy a long history, decades of years' stagnation severely restricts and affects further development. Compared with the developed horse-racing industry in America and other countries, Chinese horse-racing industry is at the initial development phase. Hence Wuhan's horse-racing industry chains have many immature and deficient aspects. Wuhan's horse-racing has attracted much attention from the international community and active participation of many countries in recent years. This provides opportunities of being geared to international conventions. In this context, Wuhan should enhance its communications and cooperation of countries with a developed horse-racing industry, learn from the mature management experience of foreign countries and Hong Kong 
and introduce high-level horse-racing talents from abroad. For one thing, it makes up for the deficiencies. For another, it avoids or reduces detours.

\section{B. Enhance Promotion Efforts and Pay Attention to Constructing Wuhan's Horse Racing Brand Culture}

Turning Wuhan's horse-racing into a brand and improving its influences are indispensable with promoting the horseracing culture. Currently, Wuhan has succeeded in holding fourteen sessions of Wuhan International Horse-racing Festivals. As the event scale expands, its influences grow. Wuhan should hold events of a higher level to secure its status as the capital of Chinese horse racing. In addition, the promotion of Wuhan's horse-racing culture should be based on Chu culture and combine the horse-racing culture and Wuhan's local culture through multi-channels to create brand horse-racing events with Chu cultural characteristics.

\section{Speeding Up the Cultivation of Professional Horse Racing Talents}

The healthy and rapid development of Wuhan's horse racing industry is indispensable with a large number of horseracing talents with management knowledge and high techniques. To meet the real demands for developing Wuhan's horse racing industry, the precondition lies in cultivating a large number of high-quality talents for the horse-racing industry. The cultivation plan should provide on-the-job training for current horse-racing operation and management talents, increase their modern knowledge and improve their professionalism. It is also necessary to recruit excellent operation and management talents from other industries and provide short-term training to teach them the development laws of horse-racing industry and make preparations for management positions in the horse-racing industry. In addition, the government should enhance national-level communications and cooperation and introduce excellent talents from abroad to develop Wuhan's horse racing industry.
Long-term cultivation should adopt a university-corporate cooperation mechanism, which requires more universities to provide majors relate to horse-racing to meet market demands.

\section{CONCLUSION}

Horse racing has gradually appeared in people's lives and become an important part of modern living in recent years in China. Compared with foreign countries, however, the development of Wuhan's horse racing industry is still at the initial phase. Thus it is necessary for Wuhan to learn mature development experience from foreign industries and set up a horse racing development model that is suitable for Chinese national conditions. This paper discusses the status of Wuhan's horse racing industry and future development direction, and then it explores the competitive advantages of Chinese horse racing enterprises in the industry to provide a referential basis for improving the operation, management and profiting capacity of Wuhan's horse racing industry.

\section{REFERENCES}

[1] Li Hai \& Xv Jian. Research on the Modernized Development of Wuhan's Horse Racing [J]. Sports Culture Guide, 2016 (02): 91 94.

[2] Ruan Wei \& Liu Yong. Analysis of Wuhan's Horse-racing Industrial Chain Development [J]. Sports Technology, 2013 (01): 24 26.

[3] Liu Xun \& Huang Qixin. Thought on Wuhan's Modern Horse Racing Industrial Development [J]. Sports Culture Guide, 2013 (12): 61 64.

[4] Xia Bo \& Xia Yunjian. Status Quo and Strategy Research of Development of Wuhan's Commercial Horse Racing Lottery [J]. Journal of Wuhan Commercial Service College, 2012 (02): 5 8.

[5] Li Yaonan. Development Advantages and Conception of Wuhan's Horse Racing Industrial Development [J]. Journal of China Three Gorges University (Edition of Humanities and Social Sciences), 2011 (04): 83 86.

[6] Zhang Hanhua, Sun Zhuo and Zhou Guanghai. Countermeasures Research on Chinese Horse Racing Industry Development [J]. Journal of Hubei Sports Technology, 2012 (01): 20 21. 